\title{
R353Q Polymorphism, Activated Factor VII, and Risk of Premature Myocardial Infarction in Japanese Men
}

\author{
Masakazu Ogawa, MD; Satoshi Abe, MD; Sadatoshi Biro, MD; Masahiko Saigo, MD; \\ Takashi Kihara, MD; Shiro Setoyama, MD**; Tatsuru Matsuoka, MD; \\ Hitoshi Toda, MD; Hiroyuki Torii, MD; Yoshihiko Atsuchi, MD; \\ Yoshifumi Toyama, MD; Shigeki Tateishi, MD; Shinichi Minagoe, MD; \\ Ikuro Maruyama, MD*; Chuwa Tei, MD
}

\begin{abstract}
Background The association between myocardial infarction (MI) and the R353Q polymorphism of the Factor VII (FVII) gene, which reportedly influences FVII concentrations, activated Factor VII (FVIIa), or FVII antigen (FVIIag), remains controversial.

Methods and Results The present case-control study in 127 Japanese men with their first MI at or before 45 years of age and 150 matched healthy controls was designed to clarify this association in premature MI. R353Q polymorphism was determined by polymerase chain reaction, and plasma concentrations of FVIIa and FVIIag were assayed. The distribution of the RR, RQ, and QQ genotypes with respect to R353Q polymorphism was 117, 10 , and 0 in the patients, and 131, 17, and 2 in the controls. The $Q$ allele was negatively associated with premature MI (odds ratio $=0.41, \mathrm{p}=0.038$ ). The plasma concentration of FVIIa was slightly higher in patients $(55.1 \pm 40.9 \mathrm{U} / \mathrm{L})$ than in controls $(44.8 \pm 20.2 \mathrm{U} / \mathrm{L})$, but not significantly $(\mathrm{p}=0.078)$; the plasma concentration of FVIIag did not differ between patients $(88.7 \pm 15.7 \%)$ and controls $(87.0 \pm 9.0 \%)(\mathrm{p}=0.557)$. Plasma FVIIa concentrations were influenced by R353Q polymorphism $(\mathrm{p}<0.001)$.
\end{abstract}

Conclusions The Q allele may be protective against premature MI. (Circ J 2004; 68: 520-525)

Key Words: Coronary risk factor; Factor VII; Genotype; Premature myocardial infarction; R353Q polymorphism

$\mathbf{F}$ actor VII (FVII) is the first enzyme in the extrinsic pathway of the blood coagulation system. Activation of the extrinsic coagulation pathway plays a key role in hemostasis, and thus FVII contributes to the occurrence of thrombotic events. Although most FVII circulates in plasma in the zymogen form, small but significant amounts of activated FVII (FVIIa) also are present, and appear to serve as a primer for triggering the extrinsic cascade $^{2-5}$ The Northwick Park Heart Study suggested that FVII coagulant activity is independently associated with risk of coronary events in middle-aged men, 6,7 and several additional studies have linked elevated concentrations of FVII in plasma to coronary heart disease ${ }^{8-14}$ Thus, FVII has become recognized as a hemostatic coronary risk factor.

Plasma FVII concentrations are influenced by both genetic and environmental factors. Green et al reported a strong association between a common polymorphism in exon 8 of the FVII gene (R353Q polymorphism) and plasma FVII1, which has been confirmed by several other studies, $8,9,16-23$ especially with respect to FVIIa. ${ }^{24}$ However, the association

(Received April 25, 2003; revised manuscript received March 2, 2004; accepted March 8, 2004)

Departments of Cardiovascular, Respiratory and Metabolic Medicine, and *Laboratory and Molecular Medicine, Graduate School of Medicine, Kagoshima University and **Kagoshima Prefectural Comprehensive Health Center, Kagoshima, Japan

Mailing address: Satoshi Abe, MD, Department of Cardiovascular, Respiratory and Metabolic Medicine, Graduate School of Medicine, Kagoshima University, 8-35-1 Sakuragaoka, Kagoshima 890-8520,

Japan. E-mail: abe@m2.kufm.kagoshima-u.ac.jp between R353Q polymorphism of the FVII gene and myocardial infarction (MI) remains controversial. The contribution of the coagulation system to the pathogenesis of MI can be studied most readily in patients with premature MI, who have less atherosclerotic coronary stenosis than elderly patients ${ }^{25-28}$

We performed a case-control study to determine whether plasma FVIIa concentrations and R353Q polymorphism are associated with risk of premature MI.

\section{Methods}

Study Population

We investigated 129 consecutive Japanese male patients treated as outpatients at Kagoshima Coronary Care Unit Network (2000-2003), with a first MI occurring before the age of 45 years (mean $\pm \mathrm{SD}, 40.4 \pm 4.5$ years old) and giving informed consent. We angiographically confirmed occlusion or significant stenosis of a coronary artery in all patients. Of the 129 patients, 2 patients, one had Kawasaki disease and another had a coronary artery anomaly, were excluded. The remaining 127 patients (premature MI patients) had a mean age of $43.9 \pm 5.1$ years at study entry, $3.3 \pm 3.8$ years after initial MI. Coronary angiography showed single-vessel disease in $93(73.2 \%)$, and multivessel disease in 34 (26.8\%). Oral anticoagulant agents were administered to 33 patients. Control subjects were 150 consecutive age-matched healthy Japanese men $(43.8 \pm 5.1$ years old at entry), who underwent a medical checkup at Kagoshima Prefectural Comprehensive Health Center and 
Table 1 Characteristics of the Premature MI Patients and Control Subjects

\begin{tabular}{lccc}
\hline \hline Characteristics & Premature MI patients & Control subjects & $p$ value \\
\hline No. & 127 & 150 & \\
Age at MI, years & $40.4 \pm 4.5$ & & $N S$ \\
Age at study entry, years & $43.9 \pm 5.1$ & $43.7 \pm 5.1$ & $<0.001$ \\
Total number of coronary risk factors* & $1.9 \pm 0.8$ & $1.4 \pm 0.8$ & $N S$ \\
Hypertension present (\%) & $17(13.4)$ & $24(16.0)$ & 0.003 \\
Hypercholesterolemia present (\%) & $79(62.2)$ & $66(44.0)$ & $<0.001$ \\
Diabetes mellitus present (\%) & $29(22.8)$ & $9(6.0)$ & 0.006 \\
Smoking history (\%) & $110(86.6)$ & $110(73.3)$ & \\
\hline
\end{tabular}

MI, myocardial infarction. Values are means \pm SD for continuous variables. NS, not significant.

*Total number of coronary risk factors represents the sum of hypertension, hypercholesterolemia, diabetes mellitus, and smoking (maximum, 4).

gave informed consent. None of the control subjects had coronary heart disease according to their medical history or electrocardiography, and none took an oral anticoagulant. This study protocol was approved by the Ethics Committee of Kagoshima University.

\section{Identification of Conventional Coronary Risk Factors}

Hypertension, hypercholesterolemia, diabetes mellitus, and smoking history were evaluated as conventional coronary risk factors. Hypertension was defined by a systolic blood pressure at entry of at least $140 \mathrm{mmHg}$, a diastolic pressure at least $90 \mathrm{mmHg}$, a past history of hypertension, or receiving antihypertensive medication. Hypercholesterolemia was defined by a serum total cholesterol concentration at entry of at least $220 \mathrm{mg} / \mathrm{dl}$, a past history of hypercholesterolemia, or receiving lipid-lowering medication. Diabetes mellitus was defined by a fasting plasma glucose concentration at entry of at least $126 \mathrm{mg} / \mathrm{dl}$, a past history of diabetes mellitus, or receiving hypoglycemic medications.

\section{Laboratory Measurements and Techniques}

Blood sampling was performed gently by 3 expert physicians at study entry. Samples were collected from all subjects between 07.00 and $11.00 \mathrm{~h}$ after an overnight fast, and also $20 \mathrm{~min}$ later in a separate syringe. Blood samples were centrifuged for $10 \mathrm{~min}\left(3,000 \mathrm{G}, 4^{\circ} \mathrm{C}\right)$ and divided into plasma, serum, and blood cells. Each was dispensed into a plastic tube respectively and frozen at $-80^{\circ} \mathrm{C}$ until analysis. Plasma concentrations of FVIIa and FVII antigen (FVIIag) were measured using a double-antibody enzymelinked immunosorbent assay (Roche Diagnostics, Basel, Switzerland) ${ }^{4}$ and a coagulation time method (Roche Diagnostics), respectively.

\section{Detection of R353Q Polymorphism}

R353Q polymorphism was detected as described by Green et al15 Amplified fragments were digested with $5 \mathrm{U}$ of MspI (New England BioLabs, Beverly, MA, USA) and then subjected to electrophoresis on a $2 \%$ agarose gel. Fragments of $205 \mathrm{bp}$ (the R allele) and $272 \mathrm{bp}$ (the Q allele) were detected. Genotypes were defined as RR, RQ, and QQ.

\section{Statistical Analysis}

Differences in baseline characteristics between the premature MI patients and control subjects were assessed using chi-square test for categorical variables and by unpaired t-test for continuous variables. Because the distributions of the plasma concentrations of FVIIa and FVIIag were skewed, logarithmic transformation was performed.
Log FVIIa and log FVIIag were compared between groups by unpaired t-test. To estimate the contribution of various risk factors to the occurrence of premature MI, multivariate logistic regression analysis was performed with FVIIa, FVIIag, hypertension, hypercholesterolemia, diabetes mellitus, and smoking status as independent variables. The frequencies of genotypes in the premature MI and control groups were compared using the chi-square test with the values predicted by Hardy-Weinberg equilibrium. Frequencies of alleles and genotypes (RR genotype vs RQ+QQ genotypes) were compared using the chi-square test between the premature MI and control groups. The odds ratio (OR) was calculated with a $95 \%$ confidence interval (95\%CI). Multivariate logistic regression analysis including hypertension, hypercholesterolemia, diabetes mellitus, and smoking status was performed to assess the association between the R353Q polymorphism and the occurrence of premature MI. The effect of the Q allele, with the $\mathrm{R}$ allele chosen as the reference allele, was analyzed by the introduction of 3 dummy variables $(0,1$, and 2$)$ coding respectively for the number of $\mathrm{Q}$ alleles. Categorical independent variables (hypertension, hypercholesterolemia, diabetes mellitus, and smoking status) also were coded as dummy variables ( 0 for absence and 1 for presence). The association of plasma FVIIa and FVIIag concentrations with each genotype was analyzed with one-way analysis of variance.

Values for continuous variables are expressed as means \pm SD. A p-value of less than 0.05 was considered to be statistical significant. All computations were carried out with the STAT View-J 5.0 (SAS Institute, NC, Cary, USA) or STATA 7.0 (Stata Corporation, College Station, USA).

\section{Results}

\section{Characteristics of the Study Population}

Characteristics of the premature MI patients and control subjects are shown in Table 1 . There was no significant difference in age at entry between the 2 groups. Patients showed significantly higher prevalences of hypercholesterolemia, diabetes mellitus, and smoking than control subjects $(\mathrm{p}<0.01)$, and had a greater number of conventional coronary risk factors than control subjects $(\mathrm{p}<0.001)$. Family history was recognized in $7.1 \%$ of MI patients.

\section{R353Q Polymorphism and Premature MI}

The frequencies of the genotypes and alleles of the $\mathrm{R} 353 \mathrm{Q}$ polymorphism are shown in Table 2. The distribution of genotypes was virtually identical to that predicted by the Hardy-Weinberg equilibrium, in both the MI patients $(p=0.644)$ and control subjects $(p=0.113)$. Because 
Table 2 Plasma FVIIa and FVIIag Concentrations, and the Distribution of Genotypes and Alleles of R353Q Polymorphism of the Factor VII Gene Between the Premature MI Patients and Control Subjects: Risk of Premature MI

\begin{tabular}{lcc}
\hline \hline Variable & Premature MI patients & Control subjects \\
\hline FVIIa $(U / L)$ & $55.1 \pm 40.7$ & $44.8 \pm 20.2$ \\
FVIIag $(\%)$ & $88.7 \pm 15.7$ & $87.0 \pm 9.0$ \\
Genotype, no. (\%) & & \\
$R R$ & $117(92.1)$ & $131(87.3)$ \\
$R Q$ & $10(7.8)$ & $17(11.3)$ \\
$Q Q$ & $0(0)$ & $2(1.3)$ \\
$R Q+Q Q$ & $10(7.8)$ & $19(12.7)$ \\
Alleles, no. $(\%)$ & & $279(93.0)$ \\
$R$ & $244(96.1)$ & $21(7.0)$ \\
$Q$ & $10(3.9)$ &
\end{tabular}

FVIIa, activated factor VII; FVIIag, factor VII antigen; MI, myocardial infarction.

Values are means $\pm S D$ for continuous variables.
Table 3 Risk of Premature Myocardial Infarction for R353Q Polymorphism by Multivariate Logistic Regression Analysis

\begin{tabular}{llc}
\hline \hline Variable & OR $(95 \%$ CI $)$ & p value \\
\hline Q allele & $0.41(0.18-0.95)$ & 0.038 \\
Hypertension & $0.86(0.42-1.76)$ & $N S$ \\
Hypercholesterolemia & $1.87(1.13-3.10)$ & 0.016 \\
Diabetes mellitus & $5.37(2.27-12.74)$ & $<0.001$ \\
Smoking status & $2.43(1.25-4.70)$ & 0.009
\end{tabular}

OR, odds ratio; $C I$, confidence interval.

The multivariate logistic regression analysis included the $Q$ allele of $R 353 Q$ polymorphism and hypertension, hypercholesterolemia, diabetes mellitus and smoking history. All independent variables were coded as dummy variables (for $R 353 Q$ polymorphism, 0 for $R R, 1$ for $R Q$, and 2 for $Q Q ;$ for hypertension, hypercholesterolemia, diabetes mellitus, and smoking history: 0 for absence and 1 for presence).
A

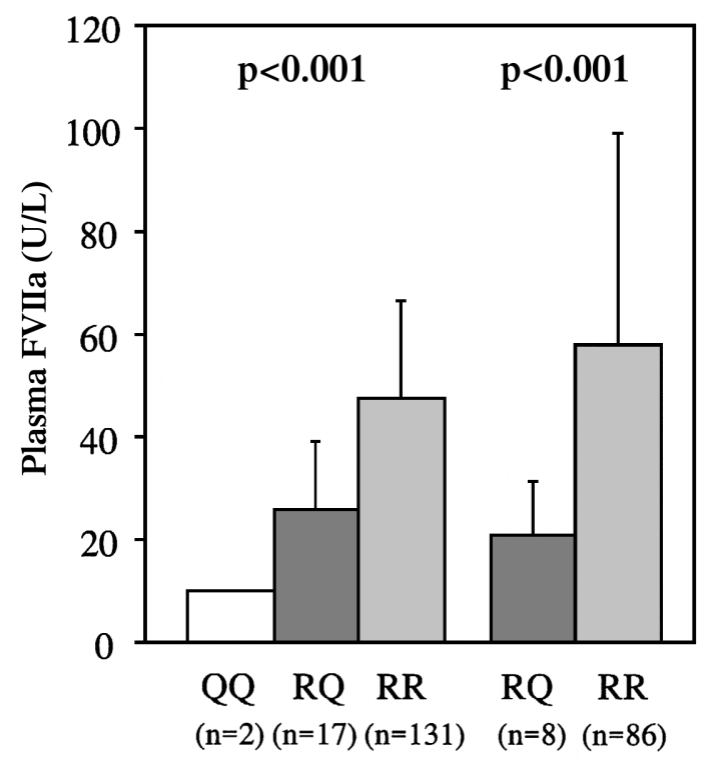

Controls Premature MI
B

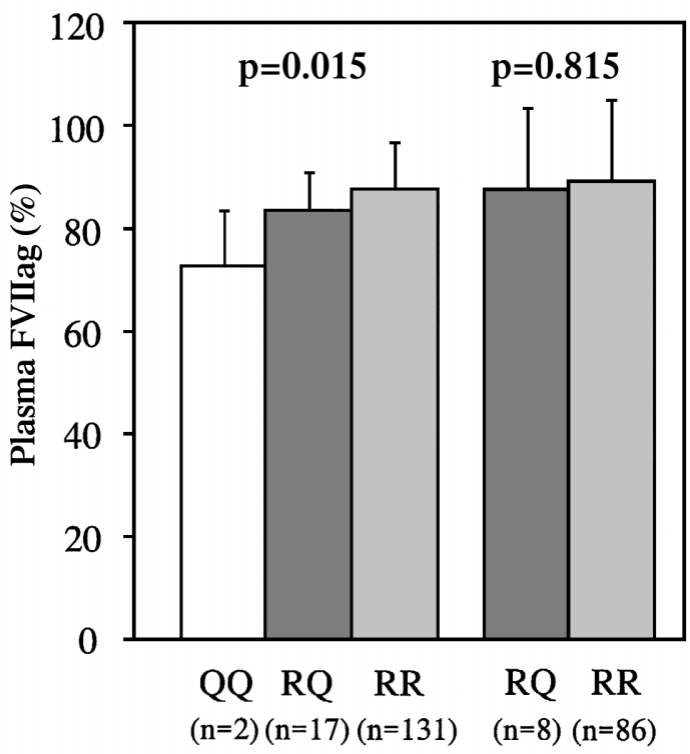

Controls

\section{Premature MI}

Fig 1. Plasma concentrations of FVIIa (A) and FVIIag (B) according to R353Q polymorphism. QQ, RQ, and RR refer to the respective genotypes. Values are means \pm SD. FVIIa, activated factor VII; FVIIag, factor VII antigen; MI, myocardial infarction.

the QQ genotype was not seen in premature MI patients, the distribution of genotypes was compared between the $\mathrm{RR}$ and the RQ+QQ genotypes. No significant difference in frequency of the $\mathrm{RQ}+\mathrm{QQ}$ genotype or the $\mathrm{Q}$ allele was seen between the 2 groups.

The results of logistic regression analysis including the $\mathrm{Q}$ allele, hypertension, hypercholesterolemia, diabetes mellitus, and smoking are shown in Table 3. In the multivariate analysis including the 4 conventional coronary risk factors, the Q allele was significantly associated with the occurrence of premature MI (OR 0.41; $\mathrm{p}=0.038, \mathrm{r}^{2}=0.01$ ). There were no significant interactions between the $\mathrm{Q}$ allele and conventional risk factors.

Ten premature MI patients with the $\mathrm{Q}$ allele had 2.7 \pm 1.2 conventional risk factors, significantly more $(\mathrm{p}=0.002)$ than 19 control subjects with the $\mathrm{Q}$ allele $(1.5 \pm 0.7)$. All premature MI patients with the Q allele had a history of smoking, and none had hypertension. No significant difference in prevalence of diabetes mellitus or hypercholesterolemia was noted (data not shown).

\section{Plasma FVII and Premature MI}

Plasma concentrations of FVIIa and FVIlag were compared between MI patients not receiving anticoagulant agents and control subjects. The plasma FVIIa concentrations in the patients $(55.1 \pm 40.7 \mathrm{U} / \mathrm{L})$ were slightly higher than those in control subjects $(44.8 \pm 20.2 \mathrm{U} / \mathrm{L})$, but not significant $(\mathrm{p}=0.078)$. Plasma FVIIag concentrations showed no significant difference between the 2 groups $(88.7 \pm 15.7 \%$ vs $87.0 \pm 9.0 \%, \mathrm{p}=0.557)$ (Table 2$)$.

In multivariate logistic regression analysis including plasma concentrations of FVIIa and FVIIag and the presence of hypertension, hypercholesterolemia, diabetes mellitus, and past or present smoking status with respect to 
premature MI, plasma FVIIa and FVIIag concentrations showed no significant association with risk of premature MI ( $\mathrm{p}=0.102$ and 0.810 , respectively).

\section{R353Q Polymorphism and FVII}

Plasma concentrations of FVIIa and FVIIag in the various genotypes are compared in Fig 1. In the control subjects, plasma FVII concentrations for the QQ, RQ, and RR genotypes were 9.7 $\pm 0.7 \mathrm{U} / \mathrm{L}, 26.0 \pm 13.2 \mathrm{U} / \mathrm{L}$, and $47.8 \pm$ $12.3 \mathrm{U} / \mathrm{L}$, respectively. Plasma FVIIag concentrations were $72.5 \pm 10.6 \%, 83.6 \pm 7.2 \%$, and $87.6 \pm 9.0 \%$, respectively. R353Q polymorphism, then, showed significant associations with FVIIa $(\mathrm{p}<0.001)$ and FVIIag $(\mathrm{p}=0.015)$. In MI patients, plasma FVIIa concentrations for the RQ genotype $(21.0 \pm 9.8 \mathrm{U} / \mathrm{L})$ were significantly lower $(\mathrm{p}<0.001)$ than those with the RR genotype $(58.3 \pm 41.0 \mathrm{U} / \mathrm{L})$. However, plasma FVIIag concentrations showed no significant difference between the 2 genotypes $(87.5 \pm 15.7 \%$ vs $88.8 \pm 15.8 \%$, respectively, $\mathrm{p}=0.815)$.

\section{Discussion}

The findings of the multivariate logistic regression analysis that included the conventional coronary risk factors of hypertension, hypercholesterolemia, diabetes mellitus, and smoking suggest that R353Q polymorphism is significantly associated with the risk of premature MI in the present study population. Plasma FVIIa concentrations in the patients were slightly higher than those in control subjects, but not significantly. Therefore, the Q allele of R353Q polymorphism might protect against premature $\mathrm{MI}$ in Japanese men.

Several studies have suggested that FVII is a coronary risk factor6-14 but it has not been established by consensus that R353Q polymorphism of the FVII gene is associated with the risk of MI. Therefore, we conducted the present case-control study analyzing FVII genotypes. Although most FVII circulates in the zymogen form, a priming role in triggering the coagulation cascade has been assigned to the smaller amounts of circulating FVIIa ${ }^{2-5}$ Because FVIIa is the first active protease in the extrinsic pathway of the coagulation cascade, plasma FVIIa concentrations may be important for determining the occurrence of thrombotic events such as thrombosis after rupture of an atherosclerotic plaque. Kario et al reported that plasma FVIIa concentrations were increased in patients with cardiovascular disease, and Philippou et al observed increased FVIIa in patients with acute coronary syndromes ${ }^{10}$ However, the increase of FVIIa has not been sufficiently established as a hemostatic coronary risk factor. In our previous study, we found activation of the coagulation cascade, evaluated by the ratio of tissue factor and tissue factor pathway inhibitor in premature MI, but could not confirm the increase of plasma FVIIa.9

In the present study of premature MI in Japanese men, we observed significant associations for R353Q polymorphism, but not for plasma FVIIa $(\mathrm{p}=0.078)$. Many studies have not recognized associations between plasma R353Q polymorphism or FVIIa and cardiovascular disease ?3,30-34 $^{2}$ The Framingham Heart Study reported that R353Q polymorphism was not significantly associated with cardiovascular disease, and suggested that R353Q polymorphism might be in linkage disequilibrium with other polymorphisms of the FVII gene or with another as-yet-unidentified gene located near the FVII gene? 23 Recently, significant associations between polymorphisms of the FVII gene and MI, coronary artery disease, or cardiac events after intervention have been confirmed ${ }^{35-40}$ Iacoviello et al suggested that R353Q and the hypervariable region 4 polymorphisms influenced the risk of MI in families with a history of thrombosis 35 Girelli et al reported that there were significantly more heterozygotes and homozygotes for the Q and A2 alleles among those who had not had a MI than among those who had had an infarction ( $\mathrm{p}=0.01$ for $\mathrm{R} 353 \mathrm{Q})$ ? $^{36}$ However, there have been no studies showing a significant association between R353Q polymorphism of FVII and premature MI.

Among there are many studies of the polymorphisms of genes and coronary heart disease in Japanese, ${ }^{41-43}$ as far as we know there have been only 2 studies investigating the genotypes of coagulation factor VII and coronary heart disease. Tamaki et al reported that polymorphisms of factor VII gene were not associated with the risk of MI 34 whereas Shimokata et al found a significant association between FVII polymorphism and coronary artery disease, but not MI ${ }^{40}$ Therefore, we are the first to recognize a significant association with the risk of MI in Japanese.

Many studies have reported fewer stenotic atheromatous lesions on the coronary angiograms of younger MI patients compared with the elderly ${ }^{25-28}$ Because atherosclerosis plays a reduced role in premature $\mathrm{MI}$, prothrombotic factors

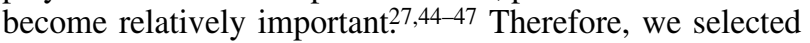
relatively young Japanese men as study subjects. In the present study, the relation of $\mathrm{R} 353 \mathrm{Q}$ polymorphism to the risk of premature MI was significant when considered together with the presence of conventional coronary risk factors. The discrepancy between our results and previous Japanese studies may be caused by the difference in the age of the study subjects. The mean ages of patients in studies by Tamaki et al and Shimokata et al were 59 years and 63 years, respectively. Because the role of FVII in the pathogenesis of MI might be less significant than conventional coronary risk factors in elderly Japanese, the previous 2 Japanese studies that included many elderly patients did not recognize the significant associations between $\mathrm{R} 353 \mathrm{Q}$ polymorphism and MI. In contrast to hypercholesterolemia, diabetes mellitus, and smoking, all of which increased risk in this study, the $\mathrm{Q}$ allele seemed to be protective against premature MI. In contrast to the present results, when Moor et al and Ardissino et al assessed R353Q polymorphism in young survivors of MI, they found no significant differences in the prevalence of $\mathrm{R} 353 \mathrm{Q}$ polymorphism between patients with premature MI and control subjects?,32 In Taiwan, Li et al reported that R353Q polymorphism was an independent risk predictor of subsequent cardiac events in the young survivors of MI, but there was no difference in the prevalence of this polymorphism between patients and controls 39 The reason for disagreement between these study findings is not clear, but may involve differences of ethnicity and the prevalence of established coronary risk factors in the subjects.

Premature MI patients with the Q allele who otherwise might have had a reduced risk of MI had a significantly greater number of conventional coronary risk factors than control subjects with the Q allele. Recently, Iacoviello et al reported that smoking doubled the risk of MI in subjects with the Q allele.8 In the present study, all premature MI patients with the $\mathrm{Q}$ allele were current or former smokers. The $\mathrm{Q}$ allele presumably could not counter the increased risk of MI from smoking. 


\section{Study Limitations}

The study was retrospective in design and had small statistical power $(0.28)$ because of its small scale. We need more than 450 young MI patients to obtain results with sufficient statistical power (type II error $<0.20$ ) and we will continue the present study protocol to obtain a sufficient number of patients. Although the distribution of the $\mathrm{Q}$ allele in the control subjects was similar to that previously described in Japanese $(12.6 \%$ by Tamaki et al; $17.6 \%$ by Shimokawa et al) $20,21,35,40$ the number of controls in our study was also low. Therefore, we cannot establish the FVII gene as the protective factor of MI. Large prospective epidemiologic studies are necessary to clarify the associations between polymorphism of the FVII gene, plasma FVIIa, and risk of MI.

In addition, among several polymorphisms we examined only the R353Q polymorphism of the FVII gene. Other polymorphisms of the FVII gene such as the hypervariable region $4^{49}$ and the decanucleotide insertion/deletion polymorphism, $37,50-52$ which is located in the promoter region of the FVII gene and influences its transcription, may have influenced the association. Recently, Peyvandi et al reported that a novel polymorphism in intron 1a of the FVII gene (G73A) might protect against premature MI53 Therefore, these polymorphisms of the FVII gene also need to be analyzed. Because antiplatelet agents do not have direct effects on the coagulation cascade, we measured factor VII concentrations without interrupting these agents, which were being administered to the majority of cases. To strictly exclude the effects of antiplatelet agents, it is necessary to take blood samples from patients not receiving antiplatelet agents.

In conclusion, R353Q polymorphism of FVII, which importantly influences plasma FVIIa concentrations, may protect against premature MI.

\section{Acknowledgments}

We thank Drs Tsuminori Yamashita, Masato Maeda, Hiroshi Kaieda, Tsuyoshi Yamaguchi, Seiki Harada, Hiroyuki Fujisaki, Hideaki Fukunaga, Hirohisa Shono, Toshiko Maki, Tetsuro Muranaga, Kozo Shiraishi, and Kiyotake Arikawa for their kind help. We also thank Ms Noriko Yoshihara, and $\mathrm{Mr}$ Hirobumi Okamura for measuring the biochemical parameters.

\section{References}

1. Fuster V, Corti R, Badimon JJ. Therapeutic targets for the treatment of atherothrombosis in the new millennium: Clinical frontiers in atherosclerosis research. Circ J 2002; 66: 783-790.

2. Seligsohn U, Kasper CK, Osterud B, Rapaport SI. Activated factor VII: Presence in factor IX concentrates and persistence in the circulation after infusion. Blood 1979; 53: 828-837.

3. Nakagaki T, Foster DC, Berkner KL, Kisiel W. Initiation of the extrinsic pathway of blood coagulation: Evidence for the tissue factor dependent autoactivation of human coagulation factor VII. Biochemistry 1991; 30: 10819-10824.

4. Morrissey JH, Macik BG, Neuenschwander PF, Comp PC. Quantitation of activated factor VII levels in plasma using a tissue factor mutant selectively deficient in promoting factor VII activation. Blood 1993; 81: $734-744$.

5. Morrissey JH. Tissue factor interactions with factor VII: Measurement and clinical significance of factor VIIa in plasma. Blood Coagul Fibrinol 1995; 6: S14-S19.

6. Meade TW, Mellows S, Brozovic M, Miller GJ, Chakrabarti RR, North WRS, et al. Haemostatic function and ischaemic heart disease: Principal results of the Northwick Park Heart Study. Lancet 1986; 2: $533-537$.

7. Meade TW, Ruddock V, Stirling Y, Chakrabarti R, Miller GJ. Fibrinolytic activity, clotting factors, and long-term incidence of ischaemic heart disease in the Northwick Park Heart Study. Lancet 1993; 342: 1076-1079.
8. Moor E, Silveira A, van't Hooft F, Suontaka AM, Eriksson P, Blomback M, et al. Coagulation factor VII mass and activity in young men with myocardial infarction at a young age: Role of plasma lipoproteins and factor VII genotype. Arterioscler Thromb Vasc Biol 1995; 15: 655-664.

9. Kario K, Miyata T, Sakata T, Matsuo T, Kato H. Fluorogenic assay of activated factor VII: Plasma factor VIIa levels in relation to arterial cardiovascular diseases in Japanese. Arterioscler Thromb 1994; 14: 265-274.

10. Philippou H, Adami A, Amersey RA, Stubbs PJ, Lane DA. A novel specific immunoassay for plasma two-chain factor VIIa: Investigation of FVIIa levels in normal individuals and in patients with acute coronary syndromes. Blood 1997; 89: 767-775.

11. Hoffman CJ, Miller RH, Lawson WE, Hultin MB. Elevation of factor VII activity and mass in young adults at risk of ischemic heart disease. J Am Coll Cardiol 1989; 14: 941-946.

12. de Sousa JC, Azevedo J, Soria C, Barros F, Ribeiro C, Parreira F, et al. Factor VII hyperactivity in acute myocardial thrombosis: A relation to the coagulation activation. Thromb Res 1988; 51: 165-173.

13. Redondo M, Warzke HH, Stucki B, Sulzer I, Biasiutti FD, Binder $\mathrm{BR}$, et al. Coagulation factors II, V, VII, and X, prothrombin gene $20210 \mathrm{G} \rightarrow$ A transition, and factor V Leiden in coronary artery disease: High factor $\mathrm{V}$ clotting activity is an independent risk factor for myocardial infarction. Arterioscler Thromb Vasc Biol 1999; 19: $1020-1025$.

14. Broadhurst P, Kelleher C, Hughes L, Imeson JD, Raftery EB. Fibrinogen, factor VII clotting activity and coronary artery disease severity. Atherosclerosis 1990; 85: 169-173.

15. Green F, Kelleher C, Wilkes H, Temple A, Meade T, Humphries S. A common genetic polymorphism associated with lower coagulation factor VII levels in healthy individuals. Arterioscler Thromb 1991; 11: $540-546$.

16. Saha N, Liu Y, Heng CK, Hong S, Low PS, Tay JSH. Association of factor VII genotype with plasma factor VII activity and antigen levels in healthy Indian adults and interaction with triglycerides. Arterioscler Thromb 1994; 14: 1923-1927.

17. de Maat MPM, Green F, de Knijff P, Jespersen J, Kluft C. Factor VII polymorphisms in populations with different risks of cardiovascular disease. Arterioscler Thromb Vasc Biol 1997; 17: 1918-1923.

18. Bernardi F, Marchetti G, Pinotti M, Arcieri P, Baroncini C, Papacchini M, et al. Factor VII gene polymorphisms contribute about one third of the factor VII levels variation in plasma. Arterioscler Thromb Vasc Biol 1996; 16: 72-76.

19. Hunault M, Arbini AA, Lopaciuk S, Carew JA, Bauer KA. The Arg353Gln polymorphism reduces the level of cagulation factor VII: In vivo and in vitro studies. Arterioscler Thromb Vasc Biol 1997; 17: $2825-2829$.

20. Takamiya O. Genetic polymorphism $(\mathrm{Arg} 353 \mathrm{~A} \rightarrow \mathrm{Gln})$ in coagulation factor VII gene and factor VII levels (coagulant activity, antigen and binding ability to tissue factor) in 101 healthy Japanese. Scand J Clin Lab Invest 1995; 55: 211 - 215.

21. Kario K, Narita N, Matsuo T, Kayaba K, Tsutsumi A, Matsuo M, et al. Genetic determinants of plasma factor VII activity in the Japanese. Thromb Haemost 1995; 73: 617-622.

22. Humphries SE, Lane A, Green FR, Cooper J, Miller GJ. Factor VII coagulant activity and antigen levels in healthy men are determined by interaction between factor VII genotype and plasma triglyceride concentration. Arterioscler Thromb 1994; 14: 193-198.

23. Feng D, Tofler GH, Larson MG, O’Donnell CJ, Lipinska I, Schmitz $\mathrm{C}$, et al. Factor VII gene polymorphism, factor VII levels, and prevalent cardiovascular disease: The Framingham Heart Study. Arterioscler Thromb Vasc Biol 2000; 20: 593-600.

24. Bernardi F, Arcieri P, Bertina RM, Chiarotti F, Corral J, Pinotti M, et al. Contribution of factor VII genotype to activated FVII levels: Differences in genotype frequencies between northern and southern European populations. Arterioscler Thromb Vasc Biol 1997; 17: 2548-2553

25. Ogawa K, Numao T, Iizuka M, Yanagisawa A, Yoshino H, Ishikawa $\mathrm{K}$, et al. Angiographic and coronary risk factor analyses of Japanese patients with ischemic heart disease before age 40: A multicenter cooperative study. Jpn Circ J 1996; 60: 822-830.

26. Zimmerman FH, Cameron A, Fisher LD, Ng G. Myocardial infarction in young adults: Angiographic characterization, risk factors and prognosis (Coronary Artery Surgery Study Registry). J Am Coll Cardiol 1995; 26: 654-661.

27. Choudhury L, Marsh JD. Myocardial infarction in young patients. Am J Med 1999; 107: 254-261.

28. Yasuda T, Shimizu M, Ino H, Okeie K, Yamaguchi M, Fujino N, et al. Coronary lesion morphology and prognosis in young males with myocardial infarction with or without familial hypercholesterolemia. 
Jpn Circ J 2001; 65: 247-250.

29. Saigo M, Abe S, Ogawa M, Yamashita T, Biro S, Minagoe S, et al. Imbalance of plasminogen activator inhibitor-I/tissue plasminogen activator and tissue factor/tissue factor pathway inhibitor in young Japanese men with myocardial infarction. Thromb Haemost 2001; 86: $1197-1203$.

30. Merlini PA, Ardissino D, Oltrona L, Broccolino M, Coppola R, Mannucci PM. Heightened thrombin formation but normal plasma levels of activated factor VII in patients with acute coronary syndromes. Arterioscler Thromb Vasc Biol 1995; 15: 1675-1679.

31. Heywood DM, Ossei-Gerning N, Grant PJ. Association of factor VII: $\mathrm{C}$ levels with environmental and genetic factors in patients with ischaemic heart disease and coronary atheroma characterised by angiography. Thromb Haemost 1996; 76: $161-165$.

32. Ardissino D, Mannucci PM, Merlini PA, Duca F, Fetiveau R, Tagliabue L, et al. Prothrombotic genetic risk factors in young survivors of myocardial infarction. Blood 1999; 94: 46-51.

33. Batalla A, Alvarez R, Reguero JR, González P, Alvarez V, Cubero GI, et al. Lack of association between polymorphisms of the coagulation factor VII and myocardial infarction in middle-aged Spanish men. Int J Cardiol 2001; 80: 209-212.

34. Tamaki S, Iwai N, Nakamura Y, Tsujita Y, Kinoshita M. Variation of the factor VII gene and ischemic heart disease in Japanese subjects. Coron Artery Dis 1999; 10: 601 -606.

35. Iacoviello L, Di Castelnuovo A, de Knijff P, D’Orazio A, Amore C, Arboretti R, et al. Polymorphisms in the coagulation factor VII gene and the risk of myocardial infarction. N Engl J Med 1998; 338: 7985.

36. Girelli D, Russo C, Ferraresi P, Olivieri O, Pinotti M, Friso S, et al. Polymorphisms in the factor VII gene and the risk of myocardial infarction in patients with coronary artery disease. $N$ Engl $J$ Med 2000; 343: 774-780.

37. Di Castelnuovo A, D'Orazio A, Amore C, Falanga A, Donati MB, Iacoviello $\mathrm{L}$. The decanucleotide insertion/deletion polymorphism in the promoter region of the coagulation factor VII gene and the risk of familial myocardial infarction. Thromb Res 2000; 98: 9-17.

38. Mrozikiewicz PM, Cascorbi I, Ziemer S, Laule M, Meisel C, Stangl $\mathrm{V}$, et al. Reduced procedural risk for coronary catheter interventions in carriers of the coagulation factor VII-Gln ${ }^{353}$ gene. $J$ Am Coll Cardiol 2000; 36: 1520-1525.

39. Li YH, Chen JH, Guo HR, Tsai WC, Chao TH. Genetic risk factors associated with the prognosis of myocardial infarction in young patients. Thromb Haemost 2002; 88: 694-697.

40. Shimokata K, Kondo T, Ohno M, Takeshita K, Inden Y, Iino S, et al. Effects of coagulation factor VII polymorphisms on the coronary artery disease in Japanese: Factor VII polymorphism and coronary disease. Thromb Res 2002; 105: 493-498.

41. Sawano M, Watanabe Y, Ohmura H, Shimada K, Daida H, Mokuno $\mathrm{H}$, et al. Potentially protective effects of the Ser447-Ter mutation of the lipoprotein lipase gene against the development of coronary artery disease in Japanese subjects via a beneficial lipid profile. Jpn
Circ J 2001; 65: 310-314.

42. Takezako T, Zhang B, Serikawa T, Fan P, Nomoto J, Saku K. The D allele of the angiotensin-converting enzyme gene and reperfusioninduced ventricular arrhythmias in patients with acute myocardial infarction. Jpn Circ J 2001; 65: 603-609.

43. Taniguchi I, Yamazaki T, Wagatsuma K, Kurusu T, Shimazu Y, Takikawa K, et al. The DD genotype of angiotensin-converting enzyme polymorphism is a risk factor for coronary artery disease and coronary stent restenosis in Japanese patients. Jpn Circ J 2001; 65: 897-900.

44. Siscovick DS, Schwartz SM, Rosendaal FR, Psaty BM. Thrombosis in the young: Effect of atherosclerotic risk factors on the risk of myocardial infarction associated with prothrombotic factors. Thromb Haemost 1997; 78: 7-12.

45. Ridker PM, Vaughan DE, Stampfer MJ, Manson JE, Hennekens CH. Endogenous tissue-type plasminogen activator and risk of myocardial infarction. Lancet 1993; 341: 1165-1168.

46. Thompson SG, Kienast J, Pyke SD, Haverkate F, van de Loo JC. Hemostatic factors and the risk of myocardial infarction or sudden death in patients with angina pectoris: European Concerted Action on Thrombosis and Disabilities Angina Pectoris Study Group. $N$ Engl J Med 1995; 332: 635-641.

47. Hamsten A, Wiman B, de Faire U, Blomback M. Increased plasma levels of a rapid inhibitor of tissue plasminogen activator in young survivors of myocardial infarction. N Engl J Med 1985; 313: $1557-$ 1563.

48. Iacoviello L, Di Castelnuovo A, D'Orazio A, Donati MB. Cigarette smoking doubles the risk of myocardial infarction in carriers of a protective polymorphism in the blood coagulation factor VII gene. Thromb Haemost 1999; 81: 658.

49. Marchetti G, Gemmati D, Patracchini P, Pinotti M, Bernardi F. PCR detection of a repeat polymorphism within the F7 gene. Nucleic Acids Res 1991; 19: 4570.

50. Marchetti G, Patracchini P, Papacchini M, Ferrati M, Bernardi F. A polymorphism in the 5' region of coagulation factor VII gene (F7) caused by an inserted decanucleotide. Hum Genet 1993; 90: 575576.

51. Humphries S, Temple A, Lane A, Green F, Cooper J, Miller G. Low plasma levels of factor VIIc and antigen are more strongly associated with the 10 base pair promoter $(-323)$ insertion than the Glutamine 353 variant. Thromb Haemost 1996; 75: 567-572.

52. Dell'Acqua G, Iacoviello L, D'Orazio A, Di Bitondo R, Di Castelnuovo A, Donati MB. A polymorphic cluster in the 5' region of the human coagulation factor VII gene: Detection, frequency, and linkage disequilibrium. Thromb Res 1997; 88: 445-448.

53. Peyvandi F, Mannucci PM, Bucciarelli P, Zeinali S, Akhavan S, Sacchi E, et al. A novel polymorphism in intron 1a of the human factor VII gene (G73A): Study of a healthy Italian population and of 190 young survivors of myocardial infarction. Br J Haematol 2000; 108: $247-253$ 